\title{
Study on the relationship between the IVol-BR and the future returns of the Brazilian stock market ${ }^{\star \star *}$
}

\author{
Paloma Vanni Cainelli1 \\ (D) https://orcid.org/0000-0003-0752-3376 \\ Email: pcainelli@yahoo.com
}

\author{
Antonio Carlos Figueiredo Pinto ${ }^{2}$ \\ (D) https://orcid.org/0000-0002-1452-1240 \\ Email: figueiredo@iag.puc-rio.br \\ Marcelo Cabús Klötzle² \\ (D) https://orcid.org/0000-0002-5463-6333 \\ Email: klotzle@iag.puc-rio.br
}

\author{
${ }^{1}$ Autonomous researcher, Rio de Janeiro, RJ, Brazil \\ ${ }_{2}^{2}$ Pontifícia Universidade Católica do Rio de Janeiro, Escola de Negócios, Departamento de Administração, Rio de Janeiro, RJ, Brazil
}

Received on 04.30.2019 - Desk acceptance on 06.25.2019 - $2^{\text {nd }}$ version approved on 04.29.2020 - Ahead of print on 11.27.2020

Editor-in-Chief: Fábio Frezatti

Associate Editor: Fernanda Finotti Cordeiro

\begin{abstract}
In 2015, the Financial Economics Research Center (NEFIN) of the University of São Paulo proposed an implicit volatility index for the Brazilian stock market based on the daily prices of options for the Bovespa index (Ibovespa) and that measures the expected volatility of the Ibovespa in the next two months. The aim of this study is to determine whether this implicit volatility index can be considered an antecedent indicator of future returns of the Brazilian stock market, given that it represents the expected volatility of the Ibovespa two months into the future. This study contributes to the literature on the implicit volatility index for the Brazilian stock market, which has been scarce until now. This happens due to the recent establishment of the index and due to the fact that there is not an official one published by the B3 S.A. - Brasil, Bolsa, Balcão (B3). Given the relationship found between the Brazilian implicit volatility index and the future returns of the Ibovespa, investors could anticipate instabilities in the Brazilian market by putting together strategies to protect their investment portfolios, as well as identifying opportunities to enter and exit the market. This research corroborates in disclosing the Brazilian implicit volatility index in order for it to become more widely used in academia and in the Brazilian financial market. The increase in studies on this index may also incentivize the launch of an official implicit volatility index by the B3. The relationship between the Brazilian implicit volatility index and the future returns of the Ibovespa is examined using least squares and quantile regressions. The implicit volatility index for the Brazilian stock market could help in predicting the future returns of the Ibovespa, especially for 20-, 60-, 120-, and 250-day future returns.
\end{abstract}

Keywords: Ibovespa, IVol-BR, future returns.

Correspondence address

Paloma Vanni Cainelli

Pontifícia Universidade Católica do Rio de Janeiro, Escola de Negócios, Departamento de Administração

Rua Marquês de São Vicente, 225 - CEP 22451-900

Gávea - Rio de Janeiro - RJ - Brazil

*Article presented at the XLII ANPAD Conference, Curitiba, PR, Brazil, October of 2018.

**This study was conducted with the financial support of the Coordination for the Improvement of Higher Education Personnel (CAPES), the National Council for Scientific and Technological Development (CNPq) (305641/2019-0 and 408470/2016-0), and the Carlos Chagas Filho Research Support Foundation of the State of Rio de Janeiro (FAPERJ) (E-26/202.824/2018). 


\section{INTRODUCTION}

Implicit volatility indices based on options prices emerged after the establishment, in 1973, of the first exchange for trading listed options, the Chicago Board Options Exchange (CBOE) (Fernandes et al., 2014). In 1993, the CBOE launched the first and most popular implicit volatility index, the CBOE Volatility Index (VIX), with the aim of making it a reliable reference for the expected short-term volatility of the American market and enabling futures contracts and volatility options to be structured and traded (Whaley, 1993, 2009). The VIX measures the expected volatility of the American S\&P 500 index in the next 30 days and is known as the "investor fear gauge" due to the fact that it rises drastically at moments of market turbulence (Whaley, 2000).

Given the success of the VIX, the CBOE launched another two implicit volatility indices, the VXN, which measures the expected volatility of the American Nasdaq-100 in the next 30 days, and the VXD, which measures the expected volatility of the American Dow Jones Industrial Average (DJIA) index in the next 30 days. Following the example of the $\mathrm{CBOE}$, other financial markets have established their own implicit volatility indices, for example the VDAX in Germany for the DAX 30 German stock exchange index and the VFTSE in the United Kingdom for the FTSE100 British stock exchange index, among others.

In Brazil, there is not yet any official implicit volatility index published by the B3. However, due to the importance of measuring the expected movements of the Brazilian stock market, the Financial Economics Research Center (NEFIN) of the University of São Paulo (USP) proposed, in 2015, an implicit volatility index, the IVol-BR, based on the daily prices of the options for the Bovespa index (Ibovespa) and that measures the expected volatility of the Ibovespa in the next two months. Its calculation methodology follows the same one as the VIX, with some adjustments, in order to reflect the particular characteristics of the Brazilian options market (Astorino et al., 2017). The details of the IVol-BR calculation can be found on the NEFIN website (http://www.nefin.com.br).

The CBOE publishes an implicit volatility index for the Brazilian market, the CBOE Brazil ETF Volatility Index (VXEWZ). This index is calculated based on the options for the IShares MSCI Brazil ETF (EWZ), a dollar fund that replicates the Ibovespa. However, the VXEWZ reflects both the volatility of the Brazilian stock market and the exchange rate volatility, given that the EWZ is quoted in dollars. The IVol-BR, therefore, better represents the implicit volatility of the Brazilian stock market, as it is calculated based on the options for the Ibovespa (Astorino et al., 2017).

The literature on implicit volatility indices is extensive, especially in the United States of America, as the CBOE was the first to introduce an implicit volatility index, the VIX. Studies on the Brazilian IVol-BR index have been scarce up to now due to its recent establishment and because it is not an official index. In intention with this study is to extend the work of Astorino et al. (2017), broadening the knowledge on the IVol-BR and its relationship with the future returns of the Ibovespa. Therefore, this study collaborates in divulging the IVol-BR in order for it to be more widely used in academia and in the Brazilian stock market. The increase in research related to the IVol-BR and other implicit volatility indices for the Brazilian market may incentivize the publication of an official implicit volatility index by the B3 and, in the future, the launch of derivatives, for example futures and options for the implicit volatility index.

This research uses regressions to investigate (i) the relationship between the IVol-BR and the future returns of the Ibovespa in different periods of the Brazilian market, (ii) the relationship between various intensities of the IVolBR and the future returns of the Ibovespa, and (iii) the effects of the IVol-BR at different levels of future returns of the Ibovespa. This study seeks to determine whether the IVol-BR helps in predicting the future returns of the Ibovespa. It adopts the same assumption as the studies by Giot (2005) and Rubbaniy et al. (2014) that there is some predictability in share price movements, suggesting that the market is not perfectly efficient.

According to Rubbaniy et al. (2014), the capacity to predict future returns and volatility of the market enables investors to achieve "greater performance in the (inefficient) market by anticipating its risks (volatility) and higher returns obtained by anticipating the right time to enter and exit the market" (Rubbaniy et al., 2014, p. 1). Given the relationship found between the IVol-BR and future returns, investors can anticipate instabilities in the Brazilian market, putting together strategies to protect their investment portfolios, as well as identifying opportunities to enter and exit the market.

The results obtained in this study reveal that the IVol-BR can help in predicting the future returns of the Ibovespa, especially for 20-, 60-, 120-, and 250-day future returns.

From this point onward, this study is organized as follows. Section 2 covers the literature review. Section 3 describes the research methodology adopted. Section 4 shows the results of the relationship between the IVol- 
$\mathrm{BR}$ and the future returns of the Ibovespa. Section 5 lays out the results of the robustness test. Finally, section 6 presents the conclusions of the study and suggestions for future research.

\section{THEORETICAL FRAMEWORK}

Whaley (2000) studied the contemporaneous relationship between the VIX and the American S\&P 100 index (until 2003, the VIX measured the expected volatility of the S\&P 100) in the period from 1995 to 1999 and observed that the relationship was negative. According to the author, at times of great uncertainty (high volatility), investors raise the discount rates of their equity investments, causing a reduction in the present value of cash flows (dividends) and, as a result, a fall in the value of stocks. Another finding was the asymmetry. The relationship between the VIX and the S\&P 100 was stronger at times of stock market pessimism than at times of euphoria. For that reason, this index is called the "investor fear gauge" (Whaley, 2000).

In line with the research of Whaley (2000), Giot (2005) examined the contemporaneous relationship between the VIX and the S\&P 100 and the VXN and the Nasdaq-100 for the period from 1997 to 2003, obtaining the result that the relationship between the variables was negative. The relationship between the VIX and the S\&P 100 was also revealed to be asymmetrical, while the relationship between the VXN and the Nasdaq-100 was not shown to be asymmetrical. The study by Giot (2005) therefore corroborates the definition of the VIX as an investor fear gauge.

Subsequently, in a second stage of his study, the author examined the ability of the VIX (VXN) to predict the 1-, 5-, 20-, and 60-day future returns of the S\&P 100 (Nasdaq-100). The idea of analyzing the implicit volatility index as an antecedent indicator derives from the thinking of the market operators that high levels of implicit volatility indicate an oversold market and, therefore, can be seen as a sign to enter into long positions (Giot, 2005). The methodology adopted by the author was: given time $\mathrm{t}$, the VIX (VXN) is classified into 20 percentiles, ordered according to a two-year moving window of historical data observed for the VIX (VXN), and the future returns are retained. Next, the mean of the future returns is verified for each volatility level. The study revealed that higher (lower) levels of the VIX and VXN are associated with positive (negative) future returns of the markets. The implicit volatility index therefore has predictive capacity according to the results of the research.

Unlike Giot (2005) and Whaley (2000), who only analyzed the relationship between the implicit volatility indices and the American stock markets, Smales (2016) analyzed the relationship between the VIX and the various financial markets of the United States of America, Australia, and New Zealand in the period from 2001 to 2015. The author considered the S\&P 500, ASX 200, and NZX 50 stock indices, the currency indices (weighted mean value of the local currency in relation to the currencies of the country's trading partners), and the interest on the 10year government bonds of each country. The regressions showed a negative contemporaneous relationship between the VIX and the assets. Only the relationship between VIX and the dollar (USD) was positive; that is, as the VIX increases (decreases), there is appreciation (depreciation) of the dollar.

The author also investigated whether, in periods subsequent to high (low) levels of the VIX, there is the occurrence of high (low) returns on the stock markets and on interest rates, appreciation (depreciation) of the Australian (AUD) and New Zealand (NZD) dollars, and depreciation (appreciation) of the USD. Smales (2016) observed the mean of the 5-, 20-, 60-, and 120-day returns of these markets following extremely high and low VIX levels. The study concluded that the VIX has, in general, the capacity to predict the future returns of the various markets and that it would be possible to form profitable strategies such as buying stocks, AUD, and NZD or selling USD when the VIX is at high levels, and the opposite when the VIX is at low levels.

Corrado and Miller (2006) evaluated the ability of the implicit and historical volatility to predict the expected returns of the S\&P 500 index in the period from 1994 to 2003. For this, the authors estimated the Merton (1980) premium-risk ratio, using historical volatility and the VIX. Next, for each premium-risk ratio, they calculated the expected returns, which were compared with the actual returns. The results showed that when the risk was based on historical volatility, there was no significant relationship between the expected and actual returns in any period analyzed; however, when the risk was based on the implicit volatility, the relationship was positive and significant for the period from 1994 to 1998.

Copeland and Copeland (1999) showed that alternating the asset allocation strategies according to the signals given by the VIX produced positive future returns. The authors alternated (i) between portfolios composed of value stocks and growth stocks, represented, respectively, by the S\&P/Barra Value and S\&P/Barra Growth indices and (ii) between portfolios composed of large and small cap stocks, represented, respectively, by the futures contracts 
of the S\&P 500 and Value Line indices. When the VIX increased in relation to its 75-day moving average, on the following days the portfolios formed of value stocks and large cap stocks outperformed the portfolios formed of growth stocks and small cap stocks, and when the VIX decreased the opposite occurred.

Kozyra and Lento (2011) calculated indicators, such as the moving average crossover, using VIX data to generate signals for entering and exiting the S\&P 500, Nasdaq-100, and DJIA stock markets. As the technical analysis and VIX are considered forward looking, together they should, according to the authors, generate more robust forward looking signals. The results reveal that the technical analysis based on the VIX data produces profits, these being higher than those of the technical analysis based on stock prices.

Banerjee et al. (2007) analyzed the predictive capacity of the VIX from another angle. The authors used regressions to examine the relationship between the VIX and the 30- and 60-day future returns of the stock portfolios structured according to beta, size (market value), and book-to-market (ratio between the net equity and the market value of the firm), and the relationship between the VIX and the future returns of these same stock portfolios in the presence of the Carhart (1997) and Fama and French (1993) factors. The research showed that the VIX has predictive capacity in relation to the future returns for most of the portfolios analyzed, and the relationship between the VIX and future returns is stronger for the portfolios with a high beta.

The study by Banerjee et al. (2007) was limited to the period from 1986 to 2005, ignoring the financial crisis that occurred primarily in 2008. Rubbaniy et al. (2014) extended the period analyzed to 2009, including the financial crisis, and carried out a similar study to the one done by Banerjee et al. (2007). Moreover, the authors analyzed other implicit volatility indices, the VXN and the VDAX, and the relationship between the implicit volatility indices and the 1-, 5-, 20-, and 60-day future returns of the stock markets and of the stock portfolios structured according to the economic sector. The research indicated that the implicit volatility indices generally have predictive capacity in relation to the 20- and 60-day future returns, but are insignificant for shorter periods (1 and 5 days).

It is important to highlight that Copeland and Copeland (1999), Giot (2005), and Whaley (2000) analyzed the "old" VIX, currently called the VXO, while the other researchers analyzed the "new" VIX. The change of the VIX, made by the CBOE, occurred in 2003. The main points of difference between the new VIX and the old VIX are (i) the sources of volatility and (ii) the calculation methodologies (Carr $\& \mathrm{Wu}, 2006)$. The old VIX is based on the prices of the options for the S\&P 100 (OEX) and only adopts the prices of eight in-the-money options, while the new VIX is based on the prices of various options for the S\&P 500 (SPX) (Carr \& Wu, 2006; Whaley, 2009). This alteration is due to the increased operations in the SPX options market over the years, becoming more active and relevant than the OEX options market, and to the increased in-the-money and out-of-the-money SPX sell options (Whaley, 2009).

A large part of the literature on implicit volatility indices uses the VIX as the object of study. However, with the recent launch of implicit volatility indices in emerging markets, some studies have investigated the ability of these indices to predict future returns.

Bagchi (2012) examined the relationship between the Indian implicit volatility index (India VIX) and the 30- and 45-day future returns of the stock portfolios structured according to beta, size, and book-to-market for the period from 2007 to 2009. The results of the regressions revealed a positive and significant relationship between the variables.

Chandra and Thenmozhi (2015) and Lee and Ryu (2014) analyzed, respectively, the India VIX and the VKOSPI Korean implicit volatility index, conducting similar studies to that of Copeland and Copeland (1999). Chandra and Thenmozhi (2015) revealed that alternating between portfolios composed of large and mid-cap stocks, according to the signals given by the India VIX, produced positive future returns. Lee and Ryu (2014) observed the movements of the VKOSPI to alternate between the portfolios composed of value and growth stocks and between portfolios composed of large and small cap stocks. These strategies also generated positive future returns.

Astorino et al. (2017) proposed an implicit volatility index for the Brazilian market, the IVol-BR. The IVol-BR calculation methodology is based on that of the VIX, but with some adjustments, in order to reflect the low liquidity of the Brazilian options market and the reduced number of options exercises.

The authors carried out various empirical tests in order to validate the IVol-BR. First, they used regressions to reveal that the IVol-BR contains information about the future volatility of the return on the Ibovespa. Next, they broke down the square of the IVol-BR into (i) expected variance of the return and (ii) variance premium (difference between the square of the IVol$\mathrm{BR}$ and expected variance) and, based on the variance premium, they elaborated a time-varying risk-aversion measure for Brazilian investors. The research also showed, through regressions, that the variance premium and the risk-aversion measure have the capacity to predict future returns on the Ibovespa. The IVol-BR revealed little predictive capacity for returns on the Ibovespa four weeks into the future. 


\section{RESEARCH METHODOLOGY}

Primarily following the line of research of Rubbaniy et al. (2014), this study focuses on the IVol-BR. Thus, this research intends to extend the work of Astorino et al. (2017) by examining (i) the relationship between the IVol-BR and the future returns of the Ibovespa in different periods of the Brazilian market, (ii) the relationship between the various intensities of the IVol-BR and the future returns of the Ibovespa, and (iii) the effects of the IVol-BR at different levels of future returns of the Ibovespa. This study seeks to determine the predictive capacity of the IVol-BR, but in a different way from Astorino et al. (2017). These authors only determined the predictive capacity of the IVol-BR in relation to 30-day future returns, without taking into account the impact of different moments of the Brazilian stock market, the different intensities of the IVol-BR, and the various levels of future returns of the Ibovespa.

The data used in this study are the daily time series of the IVol-BR and of the Ibovespa. The analysis period chosen is from August of 2011 to September of 2018, which corresponds exactly to the data available for the IVol-BR on the NEFIN website on October $31^{\text {st }}$ of 2018 . The daily time series of the Ibovespa was taken from the Economatica ${ }^{\circledR}$ program.

The IVol-BR is calculated daily; however, on working days when there is not enough trading of options for the Ibovespa, the IVol-BR is not launched (Astorino et al., 2017). To carry out this research, a solution needs to be found for this lack of data. The linear interpolation imputation method is therefore adopted (Moritz \& BartzBeielstein, 2017; Moritz et al., 2015; Rantou et al., 2017). All the analyses of this study use the processed time series for the IVol-BR.
After processing the IVol-BR, the times series of 1-, 5-, 20-, 60-, 120-, and 250-(working)-day future returns of the Ibovespa are calculated, following the methodology found in the study by Giot (2005). Equation 1 exemplifies the calculation for the future returns of the Ibovespa:

$$
R_{t+n}=\ln \left(\operatorname{Ibov}_{t+n}\right)-\ln \left(\operatorname{Ibov}_{t}\right)
$$

in which Ibov $v_{t+n}$ is the value of the Ibovespa at time $t+$ $n, I b o v_{t}$ is the value of the Ibovespa at time $t$, and $n=1$ for 1-working-day future returns, $n=5$ for 5-workingday future returns, $n=20$ for 20-working-day future returns, $n=60$ for 60 -working-day future returns, $n=120$ for 120-working-day future returns, and $n=250$ for 250-working-day future returns.

The first relationship to be examined in this study, based on the research of Rubbaniy et al. (2014), is between the IVol-BR and the 1-, 5-, 20-, 60-, 120-, and 250-day future returns during the whole historical time series and at two different moments of the Brazilian stock market, called "bear period" and "bull period."

The historical time series of the Brazilian market, shown in Figure 1, covers the period from August of 2011 to September of 2018, which corresponds exactly to the data available on the IVol-BR on October $31^{\text {st }}$ of 2018. The low moment of the Brazilian market (bear period) covers the period from August of 2011 to January of 2016, and the high moment of the Brazilian market (bull period) covers the period from February of 2016 to September of 2018. Figure 1 points to January of 2016 as the dividing point between the bear and the bull periods in the Brazilian market.

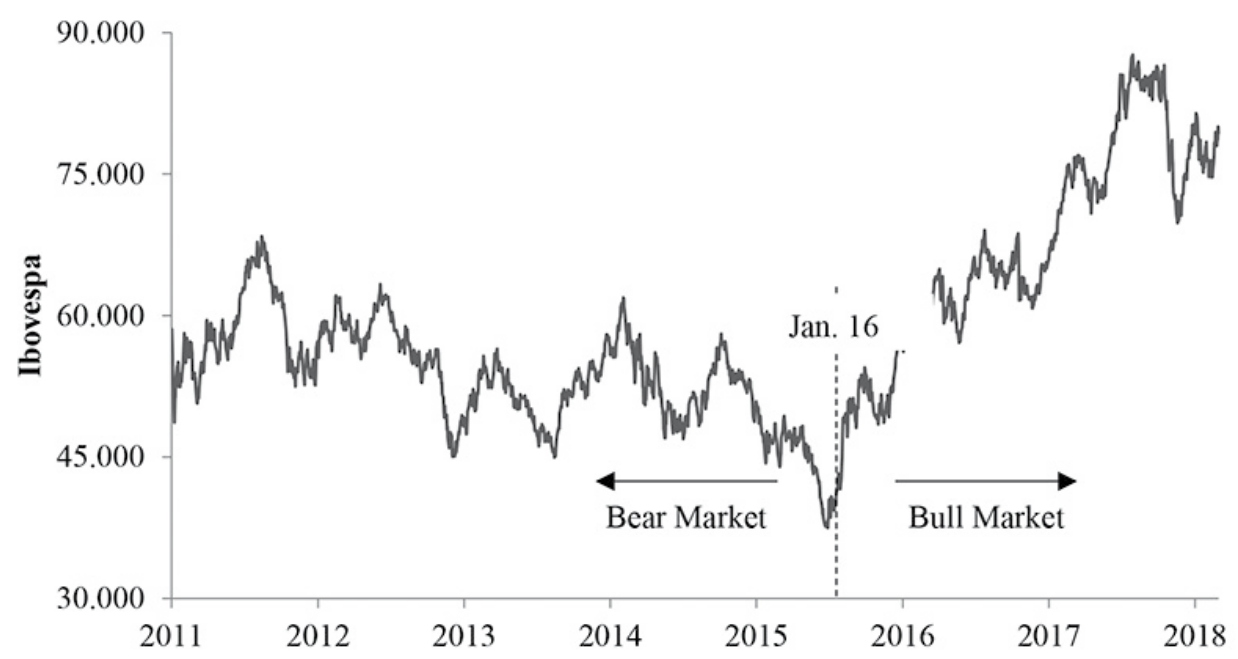

Figure 1 Historical time series of the Bovespa index (Ibovespa) from August $1^{\text {st }}$ of 2011 to September $28^{\text {th }}$ of 2018 Source: Elaborated by the authors. 
The Chow (1960) test is implemented in order to verify whether January of $2016(29 / 1 / 2016)$ can be considered a point of structural change. This test enables an examination of the stability of the parameters of a regression model using the $\mathrm{F}$ test. The null hypothesis $\left(\mathrm{H}_{0}\right)$ of the test affirms that there is no structural break (parameters are constant in the whole sample) and the alternative hypothesis $\left(\mathrm{H}_{1}\right)$ affirms that there is a structural break. The relationship between the IVol-BR and future returns of the Ibovespa during the whole historical time series and at different moments of the Brazilian stock market is analyzed using the least squares regression method, by means of equation 2 :

$$
R_{t+n}=\alpha+\beta I V l_{t}+\varepsilon_{t}
$$

in which $R_{t+n}$ is the $t+n$ days future return of the Ibovespa, $\alpha$ is the intercept, $I V_{t} l_{t}$ is the IVol-BR at time $t, \beta$ is the parameter that captures the impact of the IVol-BR on the future return of the Ibovespa, and $\varepsilon_{t}$ is the error term at time $t$.

Next, the relationship is investigated between various intensities of the IVol-BR and the 1-, 5-, 20-, 60-, 120-, and 250-day future returns of the Ibovespa using the least squares method. For that, the IVol-BR is classified into percentiles, focusing only on the extremes. The 90,95 , and 99\% percentiles represent the periods of high volatility, while the 1,5 , and $10 \%$ percentiles represent the periods of low volatility. For each percentile of the periods of high and low volatility, the corresponding 1-, 5-, 20-, 60-, 120-, and 250-day future returns of the Ibovespa are observed and retained. Subsequently, the regressions between the IVol-BR and the 1-, 5-, 20-, 60-, 120-, and 250-day future returns of the Ibovespa are run for each percentile of the high volatility (90, 95, and 99\%) and low volatility (1, 5, and $10 \%$ ) periods according to equation 2 .

The analysis of the relationship at different intensities of the IVol-BR aims to determine, just like Rubbaniy et al. (2014) in their study, whether high (low) levels of implicit volatility indicate positive (negative) future returns, thus being a signal for investors to enter the market (Giot, 2005).

Subsequently, the effects of the IVol-BR are explored at different levels of 1-, 5-, 20-, 60-, 120-, and 250-day future returns of the Ibovespa, calculating equation 2 using the quantile regression method (Koenker \& Bassett,
1978). This method enables the impact of the IVol-BR to be examined at different points of the conditional distribution of the future returns of the Ibovespa, while the least squares regression only estimates the mean effect of the IVol-BR on the conditional distribution of the future returns of the Ibovespa.

This study analyzes the effect of the IVol-BR at high and low levels of future returns of the Ibovespa, that is, the effect of the IVol-BR in the 90,95 , and $99 \%$ percentiles and in the 1,5 , and $10 \%$ percentiles of the future returns on the Ibovespa, respectively. The purpose of this analysis is to determine whether the IVol-BR has more or less impact on the different levels of future returns on the Ibovespa.

Next, a robustness test of the results obtained with these regressions is carried out, altering the specifications of equation 2.

The first step is to verify the presence of an autocorrelation in the time series of future returns using the first-order autoregressive model, known as the AR(1) model or process. The AR(1) process occurs when the value of a variable $y$ at time $t$ depends on its value at the time immediately before $(t-1)$ and on an error term $\left(u_{t}\right)$, as expressed in equation 3 :

$$
y_{t}=\alpha+\phi y_{t-1}+u_{t}
$$

The AR(1) model for the time series of future returns $\left(R_{t+n}\right)$ of the Ibovespa is modeled using equation 4 :

$$
R_{t+n}=\alpha+\phi R_{(t+n)-1}+u_{t+n}
$$

If the result of the $\mathrm{AR}(1)$ models of the time series of future returns of the Ibovespa are significant, the time series present a correlation in the first lag; that is, they show a serial autocorrelation.

The next step is to modify equation 2 , adding up the time series of the residuals generated in the AR(1) process, $u_{t+n}$, if the time series of future returns present an autocorrelation. This corrects the serial autocorrelation in the residual as shown in equation 5 .

$$
R_{t+n}=\alpha+\beta I V o l_{t}+\varepsilon_{t}+u_{t+n}
$$

Equation 5 is used to test the robustness of the results shown in the next section.

\section{RESULTS}

Before discussing the results of the regressions, the descriptive statistics of the IVol-BR and the results of the Chow (1960) test are shown in tables 1 and 2, respectively.
The mean and median of the IVol-BR during the low moment of the Brazilian market (bear period) were shown to be slightly above the mean and median for the high 
moment of the Brazilian market (bull period), as was to be expected, given that the implicit volatility indices generally increase during more turbulent periods. The asymmetry was also greater in the bear period in comparison with the bull period.
The IVol-BR time series do not have a normal distribution, as the null hypothesis of normality is rejected in the Jarque-Bera test (Jarque \& Bera, 1987). Moreover, the time series have a leptokurtic distribution and asymmetry to the right.

Table 1

Descriptive statistics of the IVol-BR in different periods of the Brazilian market

\begin{tabular}{lccc}
\hline & Bear period & Bull period & Full series \\
\hline Mean & 23.789 & 23.227 & 23.567 \\
\hline Median & 22.928 & 22.320 & 22.702 \\
\hline Maximum & 47.053 & 40.004 & 47.053 \\
\hline Minimum & 13.878 & 13.109 & 13.109 \\
\hline Standard deviation & 4.498 & 4.650 & 4.566 \\
\hline Asymmetry & 1.410 & 0.925 & 1.195 \\
\hline Kurtosis & 6.038 & 3.766 & 5.101 \\
\hline Probability & 768.302 & 117.098 & 748.596 \\
\hline
\end{tabular}

Note: Data processed in the EViews program. Bear period: from August of 2011 to January of 2016; bull period: from February of 2016 to September of 2018; full series: from August of 2011 to September of 2018.

Source: Elaborated by the authors.

The results of the Chow (1960) test, presented in Table 2 , reveal a structural break on January $29^{\text {th }}$ of 2016 for the regressions between the IVol-BR and the 5-, 20-, 60120-, and 250-day future returns of the Ibovespa. This break date can therefore be considered the dividing point between the bear and bull periods in the Brazilian market.
An analysis of the relationship between the IVol$\mathrm{BR}$ and the 1-day future returns of the Ibovespa during the bear and bull periods in the Brazilian market is not carried out, as January $29^{\text {th }}$ of 2016 was not shown to be a structural break point in the Chow (1960) test.

Table 2

Results of the Chow (1960) test

\begin{tabular}{cll}
\hline Future returns & Statistic & p-value \\
\hline 1 day & 1.997 & 0.136 \\
\hline 5 days & $11.258^{* * *}$ & 0.000 \\
\hline 20 days & $46.195^{* * *}$ & 0.000 \\
\hline 60 days & $87.353^{* * *}$ & 0.000 \\
\hline 120 days & $243.182^{* * *}$ & 0.000 \\
\hline 25 days & $540.327^{* * *}$ & 0.000 \\
\hline
\end{tabular}

Note: Data processed in the EViews program. Null hypothesis $\left(H_{0}\right)$ : there is no structural break; alternative hypothesis $\left(H_{1}\right):$ there is a structural break.

$*, * *, * *$ significance at 10,5 , and $1 \%$, respectively.

Source: Elaborated by the authors.

Table 3 presents the results of the regressions of the relationship between the IVol-BR and the future returns on the Ibovespa in different periods of the Brazilian stock market.

The results of the regressions indicate a positive and significant relationship between the 20-, 60-, 120-, and 250 -day future returns and the IVol-BR in all the periods analyzed. The relationship between the IVol-BR and the 1 - and 5-day future returns is not significant.

The regressions between the IVol-BR and the 20-, $60-, 120-$, and 250-day future returns during the low moment of the Brazilian market (bear period) and the high moment (bull period) present different values. The results for 20 days reveal a stronger influence of the 
IVol-BR on future returns during the bull period than during the bear period of the market, while the results for 60,120 , and 250 days show a stronger influence of the IVol-BR in the bear period than in the bull period of the market.
In general, the results of the regressions of Table 3 reveal that there is a relationship between the 20-, 60-, 120 -, and 250-day future returns of the Ibovespa and the IVol-BR in all the periods analyzed; that is, the coefficients were significant.

Table 3

Results of the regressions between the future returns of the Bovespa index (Ibovespa) and the IVol-BR in different periods of the Brazilian market

\begin{tabular}{|c|c|c|c|c|}
\hline & & Bear period & Bull period & Full series \\
\hline \multirow{4}{*}{1 day } & $\beta$ & - & - & 0.001 \\
\hline & $\sigma$ & - & - & 0.009 \\
\hline & p-value & - & - & 0.941 \\
\hline & $\mathrm{R}^{2}$ & - & - & 0.000 \\
\hline \multirow{4}{*}{5 days } & $\beta$ & 0.054 & 0.062 & 0.048 \\
\hline & $\sigma$ & 0.049 & 0.051 & 0.037 \\
\hline & p-value & 0.265 & 0.225 & 0.188 \\
\hline & $\mathrm{R}^{2}$ & 0.006 & 0.009 & 0.005 \\
\hline \multirow{4}{*}{20 days } & $\beta$ & $0.199^{* *}$ & $0.345^{* * *}$ & $0.218^{* * *}$ \\
\hline & $\sigma$ & 0.093 & 0.121 & 0.082 \\
\hline & p-value & 0.033 & 0.005 & 0.008 \\
\hline & $\mathrm{R}^{2}$ & 0.022 & 0.060 & 0.025 \\
\hline \multirow{4}{*}{60 days } & $\beta$ & $0.647^{* * *}$ & $0.498^{* *}$ & $0.491^{* * *}$ \\
\hline & $\sigma$ & 0.202 & 0.206 & 0.161 \\
\hline & $\mathrm{p}$-value & 0.001 & 0.016 & 0.002 \\
\hline & $\mathrm{R}^{2}$ & 0.071 & 0.059 & 0.043 \\
\hline \multirow{4}{*}{120 days } & $\beta$ & $1.145^{* * *}$ & $0.850^{* * *}$ & $0.870^{* * *}$ \\
\hline & $\sigma$ & 0.198 & 0.216 & 0.182 \\
\hline & $p$-value & 0.000 & 0.000 & 0.000 \\
\hline & $\mathrm{R}^{2}$ & 0.161 & 0.132 & 0.089 \\
\hline \multirow{4}{*}{250 days } & $\beta$ & $1.214^{* * *}$ & $0.816^{* * *}$ & $0.962^{* * *}$ \\
\hline & $\sigma$ & 0.288 & 0.218 & 0.271 \\
\hline & $\mathrm{p}$-value & 0.000 & 0.000 & 0.000 \\
\hline & $\mathrm{R}^{2}$ & 0.131 & 0.200 & 0.066 \\
\hline
\end{tabular}

Note: Data processed in the EViews program. Results of the least squares regressions according to the equation

$R_{t+n}=\alpha+\beta 1 \mathrm{Vol}_{t}+\varepsilon_{t}$. Bear period: from August of 2011 to January of 2016; bear period: from February of 2016 to September of 2018; full series: from August of 2011 to September of 2018. The Newey and West (1987) method was applied to the standard errors of the estimators, thus avoiding the effects of heteroscedasticity and autocorrelation.

*,**,** = significance at 10,5 , and $1 \%$, respectively.

Source: Elaborated by the authors.

Table 4 presents the results of the regressions of the relationship between the various intensities of the IVol$\mathrm{BR}$ and the future returns of the Ibovespa.

The results of the regressions reveal that the relationship between the various intensities of the IVol-BR and the future returns of the Ibovespa is generally not significant.
In light of these results, the IVol-BR did not show predictive capacity in relation to the future returns of the Ibovespa when at extremely high and low levels of volatility. Therefore, it cannot be affirmed that high (low) levels of volatility are a signal for investors to enter the market and obtain positive (negative) future returns. 
Table 4

Results of the regressions between the different intensities of the IVol-BR and the future returns of the Bovespa index (Ibovespa)

\begin{tabular}{|c|c|c|c|c|c|c|c|}
\hline & \multicolumn{7}{|c|}{ Percentile (IVol-BR) } \\
\hline & & $1 \%$ & $5 \%$ & $10 \%$ & $90 \%$ & $95 \%$ & $99 \%$ \\
\hline \multirow{4}{*}{1 day } & $\beta$ & -0.141 & -0.115 & -0.061 & -0.029 & -0.011 & -0.256 \\
\hline & $\sigma$ & 0.264 & 0.091 & 0.074 & 0.049 & 0.084 & 0.254 \\
\hline & p-value & 0.599 & 0.207 & 0.409 & 0.552 & 0.895 & 0.328 \\
\hline & $\mathrm{R}^{2}$ & 0.015 & 0.012 & 0.004 & 0.002 & 0.000 & 0.081 \\
\hline \multirow{4}{*}{5 days } & $\beta$ & 0.701 & $0.413^{* *}$ & 0.139 & -0.037 & 0.000 & 0.208 \\
\hline & $\sigma$ & 0.507 & 0.201 & 0.138 & 0.090 & 0.149 & 0.543 \\
\hline & $\mathrm{p}$-value & 0.183 & 0.043 & 0.313 & 0.677 & 0.999 & 0.706 \\
\hline & $\mathrm{R}^{2}$ & 0.059 & 0.037 & 0.005 & 0.001 & 0.000 & 0.010 \\
\hline \multirow{4}{*}{20 days } & $\beta$ & 1.375 & 0.778 & 0.106 & 0.235 & 0.215 & 0.692 \\
\hline & $\sigma$ & 1.922 & 0.573 & 0.436 & 0.152 & 0.197 & 0.573 \\
\hline & $\mathrm{p}$-value & 0.484 & 0.178 & 0.809 & 0.125 & 0.278 & 0.244 \\
\hline & $\mathrm{R}^{2}$ & 0.037 & 0.022 & 0.000 & 0.013 & 0.012 & 0.060 \\
\hline \multirow{4}{*}{60 days } & $\beta$ & 3.982 & $1.429 *$ & -0.113 & $-0.704^{* *}$ & -0.289 & 0.938 \\
\hline & $\sigma$ & 2.381 & 0.827 & 0.781 & 0.275 & 0.349 & 1.030 \\
\hline & $\mathrm{p}$-value & 0.112 & 0.088 & 0.885 & 0.012 & 0.411 & 0.376 \\
\hline & $\mathrm{R}^{2}$ & 0.124 & 0.027 & 0.000 & 0.049 & 0.010 & 0.051 \\
\hline \multirow{4}{*}{120 days } & $\beta$ & 4.963 & 1.880 & -0.782 & 0.136 & 0.025 & 1.004 \\
\hline & $\sigma$ & 3.530 & 1.185 & 1.030 & 0.283 & 0.345 & 0.948 \\
\hline & $\mathrm{p}$-value & 0.182 & 0.116 & 0.449 & 0.632 & 0.943 & 0.305 \\
\hline & $\mathrm{R}^{2}$ & 0.091 & 0.019 & 0.003 & 0.002 & 0.000 & 0.046 \\
\hline \multirow{4}{*}{250 days } & $\beta$ & 1.547 & -0.759 & $-3.717^{* * *}$ & $-1.147^{* * *}$ & $-1.665^{* * *}$ & 0.122 \\
\hline & $\sigma$ & 8.417 & 1.741 & 1.212 & 0.388 & 0.525 & 1.434 \\
\hline & $\mathrm{p}$-value & 0.858 & 0.664 & 0.003 & 0.004 & 0.002 & 0.933 \\
\hline & $\mathrm{R}^{2}$ & 0.003 & 0.002 & 0.058 & 0.051 & 0.096 & 0.000 \\
\hline
\end{tabular}

Note: Data processed in the EViews program. Results of the least squares regressions according to the equation $R_{t+n}=\alpha+\beta 1 \mathrm{Vol}_{t}+\varepsilon_{t^{*}}$ 90, 95, and 99\% percentiles: periods of high volatility; 1,5 , and $10 \%$ percentiles: periods of low volatility. The Newey and West (1987) method was applied to the standard errors of the estimators, thus avoiding the effects of heteroscedasticity and autocorrelation.

$*, * *, * * *=$ significance at 10,5 , and $1 \%$, respectively.

Source: Elaborated by the authors.

Table 5 presents the results of the regressions of the effects of the IVol-BR at different levels of future returns of the Ibovespa. The 90, 95, 99\% percentiles represent the high levels of future returns of the Ibovespa. The 1, 5, and $10 \%$ percentiles represent the low levels of future returns of the Ibovespa, composed of negative future returns.

The results of the regressions indicate a significant and positive relationship between the IVol-BR and high levels of future returns of the Ibovespa. A greater influence is noted in the $99 \%$ percentile of the IVol-BR on the 5-, 20-, 60-, and 250-day future returns in comparison to the other percentiles, where a 1 percentage point increase in the IVol-BR is associated with a $0.343 \%$ increase in the 5 -day future returns, a $0.767 \%$ increase in the 20 -day future returns, a $1.234 \%$ increase in the 60 -day future returns, and a $2.034 \%$ increase in the 250-day future returns.

At low levels of future returns, the results of the regressions are mixed. Of the 18 coefficients obtained, five reveal that there is a significant relationship between the IVol-BR and the future returns of the Ibovespa. On the other hand, five coefficients indicate a significant and negative relationship (an increase in the IVol-BR increases the negative future returns) and eight coefficients indicate a significant and positive relationship (an increase in the IVol-BR reduces the negative future returns). A greater influence of the IVol- 
$\mathrm{BR}$ is noted in the $1 \%$ percentile over the 1 - and 120 -day future returns in comparison with the other percentiles, where a 1 percentage point increase in the IVol-BR is associated with a $0.139 \%$ increase in the 1 -day negative future returns and a $1.168 \%$ reduction in the 120 -day negative future returns.

The IVol-BR generally acts as an antecedent indicator of the future returns of the Ibovespa more significantly at high levels of future returns than at low levels of future returns on the Ibovespa. At high levels of future returns on the Ibovespa, the IVol-BR presented a significant and positive effect. Moreover, the coefficients of the regressions at high levels of future returns presented higher absolute values than those of the coefficients of the regressions at low levels of future returns, except for 1- and 120day future returns. At low levels of future returns on the Ibovespa, the IVol-BR presented a varied effect and, in some cases, it did not present any influence.

Table 5

Results of the quantile regressions between the IVol-BR and the future returns of the Bovespa index (Ibovespa)

\begin{tabular}{|c|c|c|c|c|c|c|c|}
\hline & \multicolumn{7}{|c|}{ Percentile (future returns) } \\
\hline & & $1 \%$ & $5 \%$ & $10 \%$ & $90 \%$ & $95 \%$ & $99 \%$ \\
\hline \multirow{4}{*}{1 day } & $\beta$ & $-0.139 * *$ & $-0.078^{* * *}$ & $-0.082^{* * *}$ & $0.062^{* * *}$ & $0.098^{* * *}$ & $0.112^{* * *}$ \\
\hline & $\sigma$ & 0.056 & 0.015 & 0.013 & 0.014 & 0.015 & 0.019 \\
\hline & $p$-value & 0.013 & 0.000 & 0.000 & 0.000 & 0.000 & 0.000 \\
\hline & $\mathrm{R}^{2}$ & 0.031 & 0.037 & 0.029 & 0.025 & 0.047 & 0.069 \\
\hline \multirow{4}{*}{5 days } & $\beta$ & -0.002 & $-0.116^{* * *}$ & $-0.098^{* * *}$ & $0.156^{* * *}$ & $0.256^{* * *}$ & $0.343^{* * *}$ \\
\hline & $\sigma$ & 0.031 & 0.024 & 0.024 & 0.029 & 0.030 & 0.043 \\
\hline & $\mathrm{p}$-value & 0.957 & 0.000 & 0.000 & 0.000 & 0.000 & 0.000 \\
\hline & $\mathrm{R}^{2}$ & 0.000 & 0.017 & 0.013 & 0.037 & 0.077 & 0.140 \\
\hline \multirow{4}{*}{20 days } & $\beta$ & 0.081 & 0.073 & $0.137^{* * *}$ & $0.357^{* * *}$ & $0.364^{* * *}$ & $0.767^{* * *}$ \\
\hline & $\sigma$ & 0.126 & 0.070 & 0.050 & 0.069 & 0.104 & 0.075 \\
\hline & $p$-value & 0.522 & 0.299 & 0.007 & 0.000 & 0.001 & 0.000 \\
\hline & $\mathrm{R}^{2}$ & 0.004 & 0.001 & 0.004 & 0.029 & 0.041 & 0.176 \\
\hline \multirow{4}{*}{60 days } & $\beta$ & 0.014 & $0.123^{*}$ & $0.312^{* * *}$ & $0.564^{* * *}$ & $0.557^{* * *}$ & $1.234^{* * *}$ \\
\hline & $\sigma$ & 0.091 & 0.073 & 0.117 & 0.109 & 0.143 & 0.119 \\
\hline & $\mathrm{p}$-value & 0.878 & 0.091 & 0.008 & 0.000 & 0.000 & 0.000 \\
\hline & $\mathrm{R}^{2}$ & 0.000 & 0.002 & 0.007 & 0.028 & 0.031 & 0.183 \\
\hline \multirow{4}{*}{120 days } & $\beta$ & $1.168^{* * *}$ & $0.763^{* * *}$ & $0.778^{* * *}$ & $0.482^{* * *}$ & $0.785^{* * *}$ & $1.114^{* * *}$ \\
\hline & $\sigma$ & 0.066 & 0.090 & 0.069 & 0.091 & 0.200 & 0.086 \\
\hline & $p$-value & 0.000 & 0.000 & 0.000 & 0.000 & 0.000 & 0.000 \\
\hline & $\mathrm{R}^{2}$ & 0.069 & 0.042 & 0.043 & 0.026 & 0.040 & 0.154 \\
\hline \multirow{4}{*}{250 days } & $\beta$ & $0.161^{* *}$ & 0.146 & $0.195^{* *}$ & $0.818^{* * *}$ & $1.678^{* * *}$ & $2.034^{* * *}$ \\
\hline & $\sigma$ & 0.080 & 0.091 & 0.097 & 0.204 & 0.255 & 0.116 \\
\hline & p-value & 0.045 & 0.109 & 0.044 & 0.000 & 0.000 & 0.000 \\
\hline & $\mathrm{R}^{2}$ & 0.007 & 0.002 & 0.004 & 0.029 & 0.078 & 0.201 \\
\hline
\end{tabular}

Note: Data processed in the EViews program. Results of the quantile regressions according to the equation $R_{t+n}=\alpha+\beta 1 \mathrm{Vol}_{t}+\varepsilon_{t} \cdot 90,95$, and $99 \%$ percentiles: high levels of future returns; 1,5 , and $10 \%$ percentiles: low levels of future returns; The Newey and West (1987) method was applied to the standard errors of the estimators, thus avoiding the effects of heteroscedasticity and autocorrelation.

${ }^{*}, * *, * * *$ significance at 10,5 , and $1 \%$, respectively.

Source: Elaborated by the authors. 


\section{ROBUSTNESS TEST}

With the aim of determining the robustness of the previously found results, the specifications of the regression models are modified. The serial autocorrelation in the residual is corrected and the results of the regressions are reassessed.

Table 6 presents the results for the AR(1) models, whose residuals will be used for the reanalysis of (i) the relationship between the IVol-BR and the future returns of the Ibovespa at different moments of the Brazilian market and (ii) the effects of the IVol-BR at different levels of future returns on the Ibovespa. The coefficients of Table 6 show that there is serial autocorrelation for the 5-, 20-, 60-, 120-, and 250-day future returns of the Ibovespa.

Table 6

Results of the $A R(1)$ first-order autoregressive models for the times series of future returns on the Bovespa index (Ibovespa)

\begin{tabular}{llllllll}
\hline Series of future returns & $\mathbf{1}$ day & $\mathbf{5}$ days & $\mathbf{2 0 ~ d a y s}$ & $\mathbf{6 0}$ days & $\mathbf{1 2 0}$ days & $\mathbf{2 5 0}$ days \\
\hline$\varphi$ & -0.012 & $0.801^{* * *}$ & $0.948^{* * *}$ & $0.981^{* * *}$ & $0.987^{* * *}$ & $0.992^{* * *}$ \\
\hline$\sigma$ & 0.021 & 0.010 & 0.007 & 0.005 & 0.004 & 0.003 \\
\hline$p$-value & 0.565 & 0.000 & 0.000 & 0.000 & 0.000 & 0.000 \\
\hline $\mathrm{R}^{2}$ & 0.000 & 0.630 & 0.897 & 0.963 & 0.975 & 0.986 \\
\hline
\end{tabular}

Note: Equation used: $R_{t+n}=\alpha+\varnothing R_{(t+n)-1}+u_{t+n}$. ${ }^{*},{ }^{* *},{ }^{* * *}=$ significant at 10,5 , and $1 \%$, respectively.

Source: Elaborated by the authors.

The correlograms of the time series of future returns on the Ibovespa, shown in figures $2,3,4,5,6$, and 7 , also reveal the presence of a serial autocorrelation in the first lag for the 5-, 20-, 60-, 120-, and 250-day future returns. The Q statistic of the Ljung-Box test (Ljung \& Box, 1978), shown in the penultimate column of the figures, rejects the null hypothesis of the inexistence of a serial autocorrelation at the $1 \%$ significance level for the 5-, 20-, 60-, 120-, and 250-day future returns time series and does not reject the null hypothesis for the 1-day future returns time series.

\begin{tabular}{|c|c|c|c|c|c|c|}
\hline Autocorrelation & Partial Correlation & & $A C$ & PAC & Q-Stat & Prob \\
\hline d & d & 1 & -0.012 & -0.012 & 0.2651 & 0.607 \\
\hline$\|$ & $\|$ & 2 & 0.009 & 0.009 & 0.4102 & 0.815 \\
\hline 1 & 1 & 3 & -0.034 & -0.034 & 2.5222 & 0.471 \\
\hline 1 & 1 & 4 & -0.021 & -0.022 & 3.3003 & 0.509 \\
\hline i & $\|$ & 5 & 0.019 & 0.019 & 3.9397 & 0.558 \\
\hline 1 & 1 & 6 & -0.023 & -0.023 & 4.8468 & 0.564 \\
\hline 川 & 1 & 7 & -0.008 & -0.010 & 4.9626 & 0.665 \\
\hline 1 & i & 8 & -0.020 & -0.019 & 5.6506 & 0.686 \\
\hline 中 & i & 9 & 0.016 & 0.015 & 6.1109 & 0.729 \\
\hline$\|$ & $\|$ & 10 & 0.024 & 0.023 & 7.1522 & 0.711 \\
\hline
\end{tabular}

Figure 2 Correlogram of the time series of 1-day future returns on the Bovespa index (Ibovespa) Source: EViews. 


\begin{tabular}{|c|c|c|c|c|c|c|}
\hline Autocorrelation & Partial Correlation & & $A C$ & PAC & Q-Stat & Prob \\
\hline & & 1 & 0.786 & 0.786 & 1097.3 & 0.000 \\
\hline$\square$ & 맘 & 2 & 0.572 & -0.119 & 1679.1 & 0.000 \\
\hline$\square$ & 명 & 3 & 0.351 & -0.156 & 1898.0 & 0.000 \\
\hline 吅 & 믹 & 4 & 0.146 & -0.119 & 1936.1 & 0.000 \\
\hline d & 다궁 & 5 & -0.049 & -0.153 & 1940.4 & 0.000 \\
\hline di & 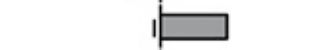 & 6 & -0.034 & 0.386 & 1942.4 & 0.000 \\
\hline d & d & 7 & -0.013 & -0.046 & 1942.7 & 0.000 \\
\hline 中 & di & 8 & 0.012 & -0.071 & 1943.0 & 0.000 \\
\hline 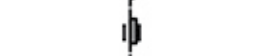 & ¿ & 9 & 0.031 & -0.054 & 1944.8 & 0.000 \\
\hline 巾 & टுं & 10 & 0.038 & -0.094 & 1947.3 & 0.000 \\
\hline
\end{tabular}

Figure 3 Correlogram of the time series of 5-day future returns on the Bovespa index (Ibovespa)

Source: EViews.

\begin{tabular}{c|rrrrrr}
\hline \hline Autocorrelation & Partial Correlation & & AC & PAC & Q-Stat & Prob \\
\hline \hline & & 1 & 0.946 & 0.946 & 1580.9 & 0.000 \\
& & & \\
\hline
\end{tabular}

Figure 4 Correlogram of the time series of 20-day future returns on the Bovespa index (Ibovespa)

Source: EViews.

\begin{tabular}{c|rrrrrr}
\hline \hline Autocorrelation & Partial Correlation & AC & PAC & Q-Stat & Prob \\
\hline \hline & & 1 & 0.981 & 0.981 & 1661.1 & 0.000 \\
& & & \\
\hline
\end{tabular}

Figure 5 Correlogram of the time series of 60-day future returns on the Bovespa index (Ibovespa)

Source: EViews. 


\begin{tabular}{c|rrrrrr}
\hline \hline Autocorrelation & Partial Correlation & & AC & PAC & Q-Stat & Prob \\
\hline \hline & & 1 & 0.987 & 0.987 & 1624.6 & 0.000 \\
& & & \\
\hline
\end{tabular}

Figure 6 Correlogram of the time series of 120-day future returns on the Bovespa index (Ibovespa)

Source: EViews.

\begin{tabular}{|c|c|c|c|c|c|c|}
\hline Autocorrelation & Partial Correlation & & $A C$ & PAC & Q-Stat & Prob \\
\hline & 此 & 1 & 0.993 & 0.993 & 1514.0 & 0.000 \\
\hline & 1 & 2 & 0.986 & 0.006 & 3007.4 & 0.000 \\
\hline & 1 & 3 & 0.979 & -0.007 & 4480.4 & 0.000 \\
\hline & 川 & 4 & 0.972 & 0.024 & 5934.2 & 0.000 \\
\hline & 中 & 5 & 0.966 & 0.051 & 7371.3 & 0.000 \\
\hline & di & 6 & 0.960 & -0.027 & 8790.6 & 0.000 \\
\hline & 1) & 7 & 0.954 & 0.035 & 10194. & 0.000 \\
\hline & 1 & 8 & 0.948 & 0.006 & 11581. & 0.000 \\
\hline & 中 & 9 & 0.943 & 0.020 & 12954. & 0.000 \\
\hline & 1 & 10 & 0.938 & -0.006 & 14312. & 0.000 \\
\hline
\end{tabular}

Figure 7 Correlogram of the time series of 250-day future returns on the Bovespa index (Ibovespa)

Source: EViews.

Table 7 shows the results for the AR(1) models, whose residuals will be used for the re-examination of the relationship between the various intensities of the IVol-BR and the future returns of the Ibovespa. For each volatility percentile, the $\mathrm{AR}(1)$ processes are calculated.
The coefficients of Table 7 indicate a serial correlation for the 1-day future returns of the Ibovespa in the $99 \%$ percentile and 5- and 250-day future returns of the Ibovespa in the $90 \%$ percentile.

Table 7

Results of the $A R(1)$ first-order autoregressive models for the time series of future returns on the Bovespa index (Ibovespa) for each percentile of the IVol-BR

\begin{tabular}{|c|c|c|c|c|c|c|c|}
\hline \multirow{2}{*}{\multicolumn{2}{|c|}{ Series of future returns }} & \multicolumn{6}{|c|}{ Percentile (IVol-BR) } \\
\hline & & $1 \%$ & $5 \%$ & $10 \%$ & $90 \%$ & $95 \%$ & $99 \%$ \\
\hline \multirow{4}{*}{1 day } & $\varphi$ & 0.261 & -0.130 & -0.046 & -0.081 & -0.039 & $0.528^{* *}$ \\
\hline & $\sigma$ & 0.234 & 0.092 & 0.064 & 0.082 & 0.112 & 0.214 \\
\hline & $\mathrm{p}$-value & 0.279 & 0.159 & 0.467 & 0.326 & 0.727 & 0.026 \\
\hline & $\mathrm{R}^{2}$ & 0.073 & 0.017 & 0.002 & 0.007 & 0.002 & 0.283 \\
\hline
\end{tabular}


Table 7

Cont.

\begin{tabular}{|c|c|c|c|c|c|c|c|}
\hline \multirow{2}{*}{\multicolumn{2}{|c|}{ Series of future returns }} & \multicolumn{6}{|c|}{ Percentile (IVol-BR) } \\
\hline & & $1 \%$ & $5 \%$ & $10 \%$ & $90 \%$ & $95 \%$ & $99 \%$ \\
\hline \multirow{4}{*}{5 days } & $\varphi$ & -0.111 & 0.139 & 0.095 & $-0.128 *$ & -0.069 & 0.124 \\
\hline & $\sigma$ & 0.269 & 0.116 & 0.080 & 0.076 & 0.116 & 0.270 \\
\hline & $\mathrm{p}$-value & 0.685 & 0.235 & 0.238 & 0.092 & 0.552 & 0.651 \\
\hline & $\mathrm{R}^{2}$ & 0.011 & 0.019 & 0.009 & 0.016 & 0.005 & 0.014 \\
\hline \multirow{4}{*}{20 days } & $\varphi$ & 0.000 & -0.069 & -0.008 & 0.012 & 0.139 & 0.155 \\
\hline & $\sigma$ & 0.281 & 0.108 & 0.074 & 0.082 & 0.112 & 0.306 \\
\hline & $\mathrm{p}$-value & 1.000 & 0.526 & 0.914 & 0.885 & 0.216 & 0.620 \\
\hline & $\mathrm{R}^{2}$ & 0.000 & 0.005 & 0.000 & 0.000 & 0.019 & 0.021 \\
\hline \multirow{4}{*}{60 days } & $\varphi$ & 0.120 & -0.180 & -0.102 & -0.092 & -0.036 & 0.225 \\
\hline & $\sigma$ & 0.269 & 0.109 & 0.074 & 0.086 & 0.130 & 0.329 \\
\hline & $\mathrm{p}$-value & 0.661 & 0.103 & 0.172 & 0.284 & 0.785 & 0.503 \\
\hline & $\mathrm{R}^{2}$ & 0.015 & 0.033 & 0.010 & 0.009 & 0.001 & 0.041 \\
\hline \multirow{4}{*}{120 days } & $\varphi$ & 0.127 & -0.213 & -0.122 & 0.116 & -0.025 & 0.117 \\
\hline & $\sigma$ & 0.268 & 0.132 & 0.081 & 0.094 & 0.136 & 0.283 \\
\hline & $\mathrm{p}$-value & 0.643 & 0.110 & 0.132 & 0.217 & 0.853 & 0.685 \\
\hline & $\mathrm{R}^{2}$ & 0.014 & 0.037 & 0.014 & 0.014 & 0.001 & 0.013 \\
\hline \multirow{4}{*}{250 days } & $\varphi$ & -0.165 & -0.199 & -0.096 & $0.144^{*}$ & 0.148 & 0.069 \\
\hline & $\sigma$ & 0.421 & 0.143 & 0.094 & 0.083 & 0.116 & 0.273 \\
\hline & $\mathrm{p}$-value & 0.705 & 0.168 & 0.311 & 0.084 & 0.208 & 0.804 \\
\hline & $\mathrm{R}^{2}$ & 0.029 & 0.041 & 0.009 & 0.021 & 0.024 & 0.005 \\
\hline
\end{tabular}

Note: Equation used: $R_{t+n}=\alpha+\varnothing R_{(t+n)-1}+u_{t+n} .90,95$, and 99\% percentiles: periods of high volatility; 1, 5, and 10\% percentiles: periods of low volatility.

$*, * *, * * *=$ significance at 10,5 , and $1 \%$, respectively.

Source: Elaborated by the authors.

Using equation 5, described in section 3 , the regressions are recalculated for the time series of future returns on the Ibovespa that presented an $\operatorname{AR}(1)$ process, as seen in Tables 6 and 7.

Table 8 presents the results of the regressions of the relationship between the IVol-BR and the future returns at different moments of the Brazilian market. In general, there were no alterations in the relationship between the IVol-BR and the future returns of the Ibovespa. It is merely verified that most of the coefficients $(\beta)$ present a value below those of Table 3 .

\section{Table 8}

Results of the regressions between the future returns of the Bovespa index (Ibovespa) and the IVol-BR in different periods of the Brazilian market

\begin{tabular}{|c|c|c|c|c|}
\hline & & Bear period & Bull period & Full series \\
\hline \multirow{4}{*}{5 days } & $\beta$ & 0.011 & 0.043 & 0.016 \\
\hline & $\sigma$ & 0.038 & 0.042 & 0.030 \\
\hline & p-value & 0.767 & 0.307 & 0.587 \\
\hline & $\mathrm{R}^{2}$ & 0.355 & 0.364 & 0.356 \\
\hline \multirow{4}{*}{20 days } & $\beta$ & $0.152^{*}$ & $0.294^{* * *}$ & $0.170^{* *}$ \\
\hline & $\sigma$ & 0.090 & 0.112 & 0.078 \\
\hline & $\mathrm{p}$-value & 0.092 & 0.009 & 0.030 \\
\hline & $\mathrm{R}^{2}$ & 0.116 & 0.146 & 0.118 \\
\hline
\end{tabular}


Table 8

Cont.

\begin{tabular}{|c|c|c|c|c|}
\hline & & Bear period & Bull period & Full series \\
\hline \multirow{4}{*}{60 days } & $\beta$ & $0.600^{* * *}$ & $0.481^{* *}$ & $0.455^{* * *}$ \\
\hline & $\sigma$ & 0.197 & 0.202 & 0.159 \\
\hline & $\mathrm{p}$-value & 0.002 & 0.018 & 0.004 \\
\hline & $\mathrm{R}^{2}$ & 0.105 & 0.084 & 0.075 \\
\hline \multirow{4}{*}{120 days } & $\beta$ & $1.105^{* * *}$ & $0.846^{* * *}$ & $0.841^{* * *}$ \\
\hline & $\sigma$ & 0.197 & 0.214 & 0.181 \\
\hline & $p$-value & 0.000 & 0.000 & 0.000 \\
\hline & $\mathrm{R}^{2}$ & 0.181 & 0.151 & 0.108 \\
\hline \multirow{4}{*}{250 days } & $\beta$ & $1.175^{* * *}$ & $0.825^{* * *}$ & $0.938^{* * *}$ \\
\hline & $\sigma$ & 0.285 & 0.217 & 0.270 \\
\hline & $\mathrm{p}$-value & 0.000 & 0.000 & 0.001 \\
\hline & $\mathrm{R}^{2}$ & 0.146 & 0.217 & 0.077 \\
\hline
\end{tabular}

Note: Results of the least squares regressions according to the equation $R_{t+n}=\alpha+B 1 \mathrm{Vol}_{t}+\varepsilon_{t}+u_{t+n}$. Bear period: from August of 2011 to January of 2016; bull period: from February of 2016 to September of 2018; full series: from August of 2011 to September of 2018. The Newey and West (1987) method was applied to the standard errors of the estimators, thus avoiding the effects of heteroscedasticity and autocorrelation.

*,**,*** = significance at 10,5 , and $1 \%$, respectively.

Source: Elaborated by the authors.

The results of the regressions between the various intensities of the IVol-BR and the 1-, 5-, and 250-day future returns of the Ibovespa, shown in Table 9, do not present any relevant differences in relation to the results of Table 4. It is merely noted that there was a fall in the absolute value of the coefficient $(\beta)$ of the relationship between the IVol-BR and the 250-day future returns in comparison with that of Table 4 .

\section{Table 9}

Results of the regressions between the different intensities of the IVol-BR and the future returns of the Bovespa index (Ibovespa)

\begin{tabular}{|c|c|c|c|c|c|c|c|}
\hline & & \multicolumn{6}{|c|}{ Percentile (IVol-BR) } \\
\hline & & $1 \%$ & $5 \%$ & $10 \%$ & $90 \%$ & $95 \%$ & $99 \%$ \\
\hline \multirow{4}{*}{1 day } & $\beta$ & - & - & - & - & - & -0.157 \\
\hline & $\sigma$ & - & - & - & - & - & 0.129 \\
\hline & $p$-value & - & - & - & - & - & 0.245 \\
\hline & $\mathrm{R}^{2}$ & - & - & - & - & - & 0.750 \\
\hline \multirow{4}{*}{5 days } & $\beta$ & - & - & - & 0.010 & - & - \\
\hline & $\sigma$ & - & - & - & 0.010 & - & - \\
\hline & $\mathrm{p}$-value & - & - & - & 0.321 & - & - \\
\hline & $\mathrm{R}^{2}$ & - & - & - & 0.984 & - & - \\
\hline \multirow{4}{*}{250 days } & $\beta$ & - & - & - & $-0.167 * * *$ & - & - \\
\hline & $\sigma$ & - & - & - & 0.055 & - & - \\
\hline & $\mathrm{p}$-value & - & - & - & 0.003 & - & - \\
\hline & $\mathrm{R}^{2}$ & - & - & - & 0.983 & - & - \\
\hline
\end{tabular}

Note: Results of the least squares regressions according to the equation $R_{t+n}=\alpha+B 1 V_{0} l_{t}+\varepsilon_{t}+u_{t+n} .90,95$, and 99\% percentiles: periods of high volatility; 1, 5, and 10\% percentiles: periods of low volatility. The Newey and West (1987) method was applied to the standard errors of the estimators, thus avoiding the effects of heteroscedasticity and serial autocorrelation.

$*, * *, * * *$ significance at 10,5 , and $1 \%$, respectively.

Source: Elaborated by the authors. 
The results of the regressions of the effects of the IVol$\mathrm{BR}$ at different levels of future returns of the Ibovespa are presented in Table 10. There was a fall in the value of most of the coefficients $(\beta)$ in relation to those of Table 5 . It is noted that the relationship between the IVol-BR and the 5 -day future returns in the $1 \%$ percentile and the 250 -day future returns in the $5 \%$ percentile is now significant, the relationship between the IVol-BR and the 60-day future returns in the $10 \%$ percentile is no longer significant, and the IVol-BR has a greater influence on the 120-day future returns in the $99 \%$ percentile and no longer any influence in the $1 \%$ percentile. Moreover, the coefficients of the regressions between the IVol-BR and the 5-day future returns at high levels of future returns do not present, as before, higher absolute values than the coefficients of the regressions at low levels of future returns.

Despite these alterations, the analysis carried out in section 4 remains; that is, at high levels of future returns, the IVol-BR generally presents a significant and positive effect, and at low levels of future returns, the IVol-BR shows a varied effect and, in some cases, does not present any influence.

Table 10

Results of the quantile regressions between the future returns of the Bovespa index (Ibovespa) and the IVol-BR

\begin{tabular}{|c|c|c|c|c|c|c|c|}
\hline & \multicolumn{7}{|c|}{ Percentile (future returns) } \\
\hline & & $1 \%$ & $5 \%$ & $10 \%$ & $90 \%$ & $95 \%$ & $99 \%$ \\
\hline \multirow{4}{*}{5 days } & $\beta$ & $-0.144 *$ & $-0.106^{* * *}$ & $-0.111^{* * *}$ & $0.117^{* * *}$ & $0.211^{* * *}$ & $0.318^{* * *}$ \\
\hline & $\sigma$ & 0.087 & 0.018 & 0.019 & 0.020 & 0.022 & 0.066 \\
\hline & $\mathrm{p}$-value & 0.099 & 0.000 & 0.000 & 0.000 & 0.000 & 0.000 \\
\hline & $\mathrm{R}^{2}$ & 0.195 & 0.217 & 0.214 & 0.224 & 0.256 & 0.304 \\
\hline \multirow{4}{*}{20 days } & $\beta$ & 0.058 & 0.029 & $0.085^{* *}$ & $0.318^{* * *}$ & $0.345^{* * *}$ & $0.689^{* * *}$ \\
\hline & $\sigma$ & 0.127 & 0.071 & 0.040 & 0.076 & 0.092 & 0.077 \\
\hline & $\mathrm{p}$-value & 0.649 & 0.687 & 0.033 & 0.000 & 0.000 & 0.000 \\
\hline & $\mathrm{R}^{2}$ & 0.056 & 0.053 & 0.055 & 0.072 & 0.085 & 0.215 \\
\hline \multirow{4}{*}{60 days } & $\beta$ & 0.044 & $0.105^{*}$ & 0.251 & $0.484^{* * *}$ & $0.427^{* * *}$ & $1.060^{* * *}$ \\
\hline & $\sigma$ & 0.084 & 0.061 & 0.159 & 0.110 & 0.125 & 0.115 \\
\hline & $\mathrm{p}$-value & 0.600 & 0.084 & 0.114 & 0.000 & 0.001 & 0.000 \\
\hline & $\mathrm{R}^{2}$ & 0.023 & 0.023 & 0.025 & 0.043 & 0.046 & 0.196 \\
\hline \multirow{4}{*}{120 days } & $\beta$ & $0.994^{* * *}$ & $0.761^{* * *}$ & $0.714^{* * *}$ & $0.445^{* * *}$ & $0.622^{* * *}$ & $1.162^{* * *}$ \\
\hline & $\sigma$ & 0.097 & 0.076 & 0.069 & 0.094 & 0.169 & 0.077 \\
\hline & $\mathrm{p}$-value & 0.000 & 0.000 & 0.000 & 0.000 & 0.000 & 0.000 \\
\hline & $\mathrm{R}^{2}$ & 0.080 & 0.052 & 0.053 & 0.039 & 0.051 & 0.171 \\
\hline \multirow{4}{*}{250 days } & $\beta$ & $0.161^{* *}$ & $0.157^{*}$ & $0.163^{*}$ & $0.914^{* * *}$ & $1.729 * * *$ & $1.988^{* * *}$ \\
\hline & $\sigma$ & 0.074 & 0.082 & 0.094 & 0.232 & 0.234 & 0.111 \\
\hline & $\mathrm{p}$-value & 0.028 & 0.055 & 0.082 & 0.000 & 0.000 & 0.000 \\
\hline & $\mathrm{R}^{2}$ & 0.016 & 0.011 & 0.012 & 0.036 & 0.088 & 0.208 \\
\hline
\end{tabular}

Note: Results of the quantile regressions according to the equation $R_{t+n}=\alpha+B 1 \mathrm{Vol}_{t}+\varepsilon_{t}+u_{t+n} .90,95$, and 99\% percentiles: high levels of future returns; 1, 5, and 10\% percentiles: low levels of future returns. The Newey and West (1987) method was applied to the standard errors of the estimators, thus avoiding the effects of heteroscedasticity and autocorrelation.

$*, * *, * * *$ significance at 10,5 , and $1 \%$, respectively.

Source: Elaborated by the authors.

In summary, after the robustness test, the results of the relationship between the IVol-BR and the future returns of the Ibovespa are generally maintained. The robustness analyses confirm the previous results described in section 4 .

\section{CONCLUSION}

This study aimed to determine whether the IVol-BR helps in predicting the 1-, 5-, 20-, 60-, 120-, and 250day future returns of the Ibovespa. Regressions were used to initially analyze (i) the relationship between the IVol-BR and the future returns of the Ibovespa in different periods of the Brazilian market, (ii) the relationship between various intensities of the IVol$\mathrm{BR}$ and the future returns of the Ibovespa, and (iii) the effects of the IVol-BR at different levels of future returns of the Ibovespa. 
The results of the relationship between the IVol-BR and the future returns of the Ibovespa in different periods of the Brazilian market indicate that the IVol-BR has predictive capacity for 20-, 60-, 120-, and 250-day future returns. The IVol-BR did not present any influence on the 1 and 5-day future returns of the Ibovespa.

The analysis of the effects of the IVol-BR at different levels of future returns of the Ibovespa shows that the IVolBR generally acts as an antecedent indicator of the future returns on the Ibovespa at high levels of future returns. At low levels of future returns, the IVol-BR presents a mixed effect and, in many cases, did not present any influence on the future returns of the Ibovespa.

The results of the relationship between the various intensities of the IVol-BR and the future returns of the Ibovespa reveal that the IVol-BR did not show predictive capacity in relation to the future returns of the Ibovespa when at high and low levels of volatility.

The robustness of the results mentioned here was tested by altering the specifications of the regression models. The serial autocorrelation in the residual was corrected and the results of the regressions were re-examined. The results of the relationship between the IVol-BR and the future returns of the Ibovespa were generally maintained. The robustness test showed that the results are robust.

This study shows that the IVol-BR can help in predicting the future returns of the Ibovespa, especially for 20-, 60-, 120-, and 250-day future returns, despite the varied effect of the IVol-BR at low levels of future returns and the non-effect of the IVol-BR on the future returns when at high and low volatility levels.

It may be necessary, as Rubbaniy et al. (2014) suggest, to consider other factors when predicting future returns of the stock market. For future studies, we recommend searching for and including other variables that can help the IVol-BR in predicting future returns on the Ibovespa. Another possible extension of this study would be the adoption of other more sophisticated econometric methods to analyze the effects of the IVol$\mathrm{BR}$ on future returns, such as the vector autoregressive (VAR) models, the Granger (1969) causality test, and the regime-switching models. Finally, we suggest including a portfolio of investments showing the financial gains using the IVol-BR as an indicator of future returns.

\section{REFERENCES}

Astorino, E. S., Chague, F., Giovannetti, B., \& Silva, M. E. D. (2017). Variance premium and implied volatility in a lowliquidity option market. Revista Brasileira de Economia, 71(1), 3-28. https://doi.org/10.5935/0034-7140.20170001

Bagchi, D. (2012). Cross-sectional analysis of emerging market volatility index (India VIX) with portfolio returns. International Journal of Emerging Markets, 7(4), 383396. https://doi.org/10.1108/17468801211264306

Banerjee, P. S., Doran, J. S., \& Peterson, D. R. (2007). Implied volatility and future portfolio returns. Journal of Banking \& Finance, 31(10), 3183-3199. https://doi.org/10.1016/j. jbankfin.2006.12.007

Brooks, C. (2014). Introductory econometrics for finance ( $3^{\text {rd }} \mathrm{ed}$.). Cambridge University Press.

Carhart, M. M. (1997). On persistence in mutual fund performance. The Journal of finance, 52(1), 57-82. https://doi. org/10.1111/j.1540-6261.1997.tb03808.x

Carr, P., \& Wu, L. (2006). A tale of two indices. The Journal of Derivatives, 13(3), 13-29. https://doi.org/10.3905/ jod.2006.616865

Chandra, A., \& Thenmozhi, M. (2015). On asymmetric relationship of India volatility index (India VIX) with stock market return and risk management. Decision, 42(1), 33-55. https://doi.org/10.1007/s40622-014-0070-0

Chow, G. C. (1960). Tests of equality between sets of coefficients in two linear regressions. Econometrica: Journal of the Econometric Society, 28(3), 591-605. https://doi. org/10.2307/1910133
Copeland, M. M., \& Copeland, T. E. (1999). Market timing: Style and size rotation using the VIX. Financial Analysts Journal, 55(2), 73-81. https://doi.org/10.2469/faj.v55. $\mathrm{n} 2.2262$

Corrado, C. J., \& Miller Jr, T. W. (2006). Estimating expected excess returns using historical and option-implied volatility. Journal of Financial Research, 29(1), 95-112. https://doi.org/10.1111/j.1475-6803.2006.00168.x

Dickey, D. A., \& Fuller, W. A. (1979). Distribution of the estimators for autoregressive time series with a unit root. Journal of the American statistical association, 74(366), 427-431. https://doi.org/10.1080/0162 1459.1979.10482531

Fama, E. F., \& French, K. R. (1993). Common risk factors in the returns on stocks and bonds. Journal of financial economics, 33(1), 3-56. https://doi.org/10.1016/0304405X(93)90023-5

Fernandes, M., Medeiros, M. C., \& Scharth, M. (2014). Modeling and predicting the CBOE market volatility index. Journal of Banking \& Finance, 40(1), 1-10. https://doi.org/10.1016/j. jbankfin.2013.11.004

Giot, P. (2005). Relationships between implied volatility indices and stock index returns. Journal of Portfolio Management, 31(3), 92-100. https://doi.org/10.3905/ jpm.2005.500363

Jarque, C. M., \& Bera, A. K. (1987). A test for normality of observations and regression residuals. International Statistical Review, 55(2), 163-172. https://doi.org/10.2307/1403192 
Koenker, R., \& Bassett, G. (1978). Regression quantiles. Econometrica: Journal of the Econometric Society, 46(1), 33-50. https://doi.org/10.2307/1913643

Kozyra, J., \& Lento, C. (2011). Using VIX data to enhance technical trading signals. Applied Economics Letters, 18(14), 1367-1370. https://doi.org/10.1080/13504851.2010.537623

Kwiatkowski, D., Phillips, P. C., Schmidt, P., \& Shin, Y. (1992). Testing the null hypothesis of stationarity against the alternative of a unit root: How sure are we that economic time series have a unit root?. Journal of econometrics, 54(1-3), 159-178. https://doi.org/10.1016/0304-4076(92)90104-Y

Lee, C., \& Ryu, D. (2014). The volatility index and style rotation: Evidence from the Korean stock market and VKOSPI. Investment Analysts Journal, 43(79), 29-39. https://doi.org/10.1080/10293523.2014.11082566

Ljung, G. M., \& Box, G. E. (1978). On a measure of lack of fit in time series models. Biometrika, 65(2), 297-303. https://doi. org/10.1093/biomet/65.2.297

Merton, R. C. (1980). On estimating the expected return on the market: An exploratory investigation. Journal of financial economics, 8(4), 323-361. https://doi.org/10.1016/0304405X(80)90007-0

Moritz, S., Sardá, A., Bartz-Beielstein, T., Zaefferer, M., \& Stork, J. (2015). Comparison of different Methods for Univariate Time Series Imputation in $R$. https://arxiv.org/ftp/arxiv/ papers/1510/1510.03924.pdf

Moritz, S., \& Bartz-Beielstein, T. (2017). ImputeTS: time series missing value imputation in R. The R Journal, 9(1), 207-218. https://doi.org/10.32614/RJ-2017-009
Newey, W. K., \& West, K. D. (1987). A simple, positive semidefinite, heteroskedasticity and autocorrelation consistent covariance matrix. Econometrica, 55(3), 703-708. https://doi. org/0012-9682(198705)55:3<703:ASPSHA > 2.0.CO;2-F

Rantou, K. E., Karagrigoriou, A., \& Vonta, I. (2017). On imputation methods in univariate time series. Mathematics in Engineering, Science \& Aerospace (MESA), 8(2), 239251. http://web.b.ebscohost.com/ehost/pdfviewer/ pdfviewer?vid=5\&sid=c7e30d76-69eb-485a-8c36191c0495c869\%40pdc-v-sessmgr04

Rubbaniy, G., Asmerom, R., Rizvi, S. K. A., \& Naqvi, B. (2014). Do fear indices help predict stock returns? Quantitative Finance, 14(5), 831-847. https://doi.org/10.1080/14697688.20 14.884722

Smales, L. A. (2016). Risk-on/Risk-off: Financial market response to investor fear. Finance Research Letters, 17, 125-134. https://doi.org/10.1016/j.frl.2016.03.010

Stock, J. H., \& Watson, M. W. (2004). Econometria (M. Rosemberg, Trad.). Addison Wesley.

Whaley, R. E. (1993). Derivatives on market volatility: Hedging tools long overdue. The Journal of Derivatives, 1(1), 71-84. https://doi.org/10.3905/jod.1993.407868

Whaley, R. E. (2000). The Investor Fear Gauge. The Journal of Portfolio Management, 26(3), 12-17. https://doi.org/10.3905/ jpm.2000.319728

Whaley, R. E. (2009). Understanding the VIX. The Journal of Portfolio Management, 35(3), 98-105. https://doi.org/10.3905/ JPM.2009.35.3.098 